\title{
Changes in immune phenotype with age impaired survival: a longitudinal approach in Alpine marmots
}

\author{
Coraline Bichet ${ }^{1}$, Corinne Régis ${ }^{2}$, Emmanuelle Gilet-Fromont ${ }^{3}$, and Aurélie Cohas ${ }^{2}$ \\ ${ }^{1} \mathrm{CEBC}$ \\ ${ }^{2} \mathrm{LBBE}$ \\ ${ }^{3}$ VetAgro Sup
}

May 21, 2021

\begin{abstract}
Recent findings suggest that immunosenescence should not be considered as a unidirectional deterioration, and that the remodeling of the immune system with age could also be adaptive. Longitudinal studies on immunosenescence in wild populations are scarce, and therefore, processes like selective disappearance cannot be easily torn apart from senescence. Using a long-term and longitudinal monitoring of a wild population of Alpine marmots, we aimed to understand within and between individual variation in the immune phenotype with age, in order to improve our knowledge about the occurrence and the consequence of immunosenescence in the wild. We tested, once controlled for a potential selective disappearance, whether individuals' immune function only decreases as they age, as expected from the disposable soma theory, or whether remodelling of the immune system does occur. Therefore, we recorded the age-specific leukocyte concentration and counts in repeatedly sampled dominant individuals and we tested the potential changes with age as well as their association with survival probabilities. The overall leukocyte concentration was stable with age, but the lymphocyte count decreased, while the neutrophil count increased, over the course of an individual's life. The leukocyte counts also predicted survival: at a given age, individuals with fewer lymphocytes but more neutrophils were more likely to die. Longitudinal studies, like the present one, are required to properly understand the patterns and consequences of immunosenescence in the wild.
\end{abstract}

\section{Changes in immune phenotype with age impaired survival: a longitudinal approach in Alpine marmots}

Coraline Bichet $^{\mathrm{a}, \mathrm{b}}$, Corinne Regis ${ }^{\mathrm{c}}$, Emmanuelle Gilot-Fromont ${ }^{\mathrm{c}, \mathrm{d}}$ and Aurélie Cohas ${ }^{\mathrm{c}, \mathrm{e}}$

${ }^{a}$ Centre d'Etudes Biologiques de Chizé, CNRS-La Rochelle Université, UMR-7372, Villiers-en-Bois, 79360France

bInstitut für Vogelforschung "Vogelwarte Helgoland" (Institute of Avian Research), Wilhelmshaven, Germany

${ }^{\mathrm{c}}$ UMR-CNRS 5558, Laboratoire Biométrie et Biologie Évolutive, Université Claude Bernard Lyon 1, Villeurbanne, France

${ }^{\mathrm{d}}$ Université de Lyon, VetAgro Sup, Marcy-l'Etoile, France

eInstitut Universitaire de France (IUF)

\section{Author for correspondence:}

C. Bichet

coraline.bichet@gmail.com 


\begin{abstract}
Recent findings suggest that immunosenescence should not be considered as a unidirectional deterioration, and that the remodeling of the immune system with age could also be adaptive. Longitudinal studies on immunosenescence in wild populations are scarce, and therefore, processes like selective disappearance cannot be easily torn apart from senescence. Using a long-term and longitudinal monitoring of a wild population of Alpine marmots, we aimed to understand within and between individual variation in the immune phenotype with age, in order to improve our knowledge about the occurrence and the consequence of immunosenescence in the wild. We tested, once controlled for a potential selective disappearance, whether individuals' immune function only decreases as they age, as expected from the disposable soma theory, or whether remodelling of the immune system does occur. Therefore, we recorded the age-specific leukocyte concentration and counts in repeatedly sampled dominant individuals and we tested the potential changes with age as well as their association with survival probabilities. The overall leukocyte concentration was stable with age, but the lymphocyte count decreased, while the neutrophil count increased, over the course of an individual's life. The leukocyte counts also predicted survival: at a given age, individuals with fewer lymphocytes but more neutrophils were more likely to die. Longitudinal studies, like the present one, are required to properly understand the patterns and consequences of immunosenescence in the wild.
\end{abstract}

\title{
Keywords
}

Ageing, immune phenotype, immune cells, immune remodeling, mammal,

\section{Marmota marmota}

\section{Introduction}

The immune system is of primary importance to control diseases throughout an individual's life, and therefore crucial to its fitness. In Vertebrates, the immune system involves different immune functions which can be divided into innate and adaptive components (Hoebe et al., 2004). The innate immune functions are the first defence against pathogens, involving phagocytic cells (e.g. neutrophils, macrophages and dendritic cells) and molecules such as cytokines, also able to activate other parts of the immune system (Akira et al., 2006; Mantovani et al., 2011; Nathan, 2006; Vivier et al., 2011). The adaptive immune functions comprise a cell-mediated immune response, with the stimulation of $\mathrm{T}$ lymphocytes, and a humoral immune response, controlled by activated B lymphocytes that can produce immunoglobulins against specific antigens (Iwasaki \& Medzhitov, 2010; Mantovani et al., 2011; Vivier et al., 2011).

Mounting an immune response carries costs (Graham, Allen, \& Read, 2005; Lochmiller \& Deerenberg, 2000; Maizels \& Nussey, 2013) and trade-offs with other life-history traits are likely to emerge (Eraud, Jacquet, \& Faivre, 2009; Graham et al., 2010; Hanssen, Hasselquist, Folstad, \& Erikstad, 2004; Lemaitre et al., 2015; Viney, Riley, \& Buchanan, 2005). Therefore, according to the theory of senescence (Medawar, 1952), and more particularly the disposable soma theory (Kirkwood \& Rose 1991), a decrease in immune performance with age is expected (reviewed in Lavoie, 2006; Shanley, Aw, Manley, \& Palmer, 2009; Simon, Hollander, \& McMichael, 2015).

Immunosenescence was mainly studied in humans and laboratory animals (Bektas, Schurman, Sen, \& Ferrucci, 2017; Frasca, Riley, \& Blomberg, 2005; Gayoso et al., 2011; Larbi et al., 2008; Noreen, Bourgeon, \& Bech, 2011; Solana et al., 2012), with the general pattern being a decline in adaptive immunity with age, while innate immunity remains unchanged and inflammatory markers increase (Bauer \& De la Fuente, 2016; Franceschi et al., 2007; Frasca, Diaz, Romero, Landin, \& Blomberg, 2011; Panda et al., 2009; Shaw, Goldstein, \& Montgomery, 2013; Simon et al., 2015). In non-model organisms, a recent review found similar trends (Peters et al., 2019). These findings suggest that the decrease in the immune functions with age could occur and impaired survival (e.g. Froy et al., 2019; Schneeberger, Courtiol, Czirjak, \& Voigt, 2014), but that a remodelling of the immune functions and 'inflammaging' (accumulation of pro-inflammatory factors, (Franceschi et al., 2018; Goto, 2008) characterized by changes in the proportion of the different cells invol- 
ved in the immune response could also take place. Such changes could lead immune changes with age to be adaptive (Fulop et al., 2018; Mueller et al., 2013; Nikolich-Zugich, 2018).

Because the immune system is complex, involving many cell types and pathways, its characterization in non-model organisms is challenging, thus limiting the study of immunosenescence in free-ranging animals (Boughton et al., 2011; Demas et al., 2011). Only few cross-sectional studies investigated the variations in the immune function with age (mammals: Abolins et al., 2018; Cheynel et al., 2017; Nussey, Watt, Pilkington, Zamoyska, \& McNeilly, 2012; birds: Hill et al., 2016; Lecomte et al., 2010; Palacios, Cunnick, Winkler, \& Vleck, 2007; Saino, Ferrari, Romano, Rubolini, \& Moller, 2003; Vermeulen, Eens, Van Dongen, \& Muller, 2017; reptiles: Massot et al., 2011; Ujvari \& Madsen, 2011; Zimmerman et al., 2013), and even less with survival (Froy et al., 2019; Hanssen et al., 2004; Schneeberger et al., 2014). However, cross-sectional studies cannot disentangle whether the observed variations arise from within-individual changes or from processes like selective disappearance (van de Pol \& Verhulst, 2006; van de Pol \& Wright, 2009). Due to this shortcoming, immunosenescence can be either hidden when it occurs or observed when it does not (Nussey, Coulson, Festa-Bianchet, \& Gaillard, 2008) leading to inappropriate conclusions regarding its evolutionary consequences.

The current lack of longitudinal studies investigating variations in immune functions with age (to the best of our knowledge, four studies: Beirne et al., 2016; Andrea L. Graham et al., 2010; Schneeberger et al., 2014; van Lieshout et al., 2020) is one of the biggest limitations to our understanding of immunosenescence in wild populations (Peters et al., 2019). In the present study, we recorded the age-specific leukocyte concentration and counts in 52 dominant individuals repeatedly sampled between 2011 and 2015 (for a total of 169 measurements) from a wild and long-term studied (1992-2018) population of Alpine marmots. We first tested whether, once controlled for a potential selective disappearance, individuals' leukocyte concentration and counts only decrease as they age as expected from the disposable soma theory or whether more complex patterns involving changes in leukocyte counts do occur. We further tested whether age variations in leukocyte concentration and counts correlated with survival probabilities using a longitudinal approach.

\section{Material and methods}

\section{Studied species}

Alpine marmots are territorial, socially monogamous and cooperatively breeding ground-dwelling squirrels (Allainé, 2000). They live in families of two to 16 individuals composed of a dominant pair monopolizing reproduction (Arnold \& Dittami, 1997; Cohas, Yoccoz, Silva, Goossens, \& Allainé, 2006; Hacklander, Mostl, \& Arnold, 2003), sexually mature ([?] 2 years) subordinates of both sexes, yearlings and pups of the year (Allaine, 2000). At sexual maturity, subordinates may keep their status, attempt to reach dominance in their natal groups or disperse to gain dominance in another territory (Lardy et al., 2012). Once an individual reaches dominance, it cannot reverse to subordinate status. Dominance is established for several years and lasts until the dominant individual is evicted or dies (Lardy et al., 2011). During the 23 years of study, only three males and one female lost their dominant status but established dominance in another territory (Lardy et al., 2011).

\section{Field methods}

As part of a long-term study at La Grande Sassiere Nature Reserve (2,340 m a.s.l., French Alps, 45o29'N, 65090 'E, see (Cohas et al., 2008) for details), we captured marmots annually, from mid-April to mid-July using live traps placed close to the main burrows to assign trapped individuals to their family. Individuals were marked with a transponder and a numbered ear-tag, combined with a coloured plastic ear-tag for dominant individuals. At each capture, individuals were tranquilized by an intramuscular injection of Zoletil $100\left(0.1 \mathrm{ml} . \mathrm{kg}^{-1}\right)$, sexed, aged, weighed and their social status was determined (large scrotum for dominant males and prominent teats for dominant females, characteristics of each sex all year round independently of reproduction). Social status was further confirmed by observations of scent-marking behaviour and territorial defence that are characteristics of dominants. Exact age was determined for the individuals born on the study site. For dominant immigrants (5 individuals), we assigned the age of three when they first reproduce, 
as marmots disperse at two years old and never reproduce before three years old. To determine individual fates, capture histories were combined with intensive observations (each family being observed on average 1 hour per day for a minimum of 30 hours per year, for details see Cohas et al., 2008). At each capture, a blood sample $\left(2 \mathrm{ml} . \mathrm{kg}^{-1}\right)$ was taken from the saphenous vein within 30 minutes after capture.

As senescence should not occur prior to first reproduction (Hamilton, 1966), we restricted the subsequent analysis to the sole dominant marmots: fully grown and reproductive individuals aged from 3 to 12 years-old (47 born on the study site and 5 immigrants, removing immigrants did not change qualitatively the results).

\section{Leukocyte concentration}

A $20 \mu \mathrm{l}$ blood filled capillary was released in $1 \mathrm{ml}$ of a kit solution (LEUKO-TIC "blue", Bioanalytic, Germany). This solution allows a microscopic count of leukocytes after the lysis of the erythrocytes and the fixation of the leukocyte nucleus colored in light blue. The leukocyte counts were done at x100 enlargement using a Malassez counting chamber by a single observer (C.R.). Only the leukocytes entirely located inside the four $1 \mathrm{~mm}^{2}$ corner squares (total volume of $4^{*} 1 \mathrm{~mm}^{2 *} 0.2 \mathrm{~mm}=0.8 \mu \mathrm{l}$ ) were counted. All the leukocyte counts were done within 24 hours after blood collection.

Between 2013 and 2015, the leukocyte concentration was determined for 79 samples from 34 dominant individuals sampled between two and three times. 23 individuals had two samples in different years and 11 individuals had three.

\section{Leukocyte counts}

Immediately upon blood collection, a drop of blood was smeared onto a slide, later stained with Giemsa stains using an aerospray (Aerospray Hematology Slide/Cytocentrifuge 7150, Wescor, France). Neutrophils, lymphocytes, monocytes, eosinophils and basophils were counted (observer: CR) up to 100 leukocytes, at 100x enlargement, according to Hawkey and Dennett's criteria (Hawkey \& Dennett, 1989). The basophil count was low for nearly all individuals $(\min =0, \max =49$, median $=0)$ and therefore excluded in the subsequent analyses.

Between 2011 and 2015, the leukocyte counts were determined for 169 blood smears from 52 dominant individuals sampled between two and five times. 18 individuals had two samples in different years, 12 had three, 13 had four, and 9 individuals had five. 33 of them were both measured for leukocyte concentration and leukocyte counts (which corresponds to 75 measurements).

\section{Statistical analyses}

All statistical analyses were performed with R 3.5.3 (R Core Team, 2014).

Variations with age

To test whether the leukocyte concentration and counts varied with age, we used the leukocyte concentration (log-transformed) as dependent variable and the age as an explanatory variable in a LMM and the counts of lymphocytes, neutrophils, monocytes and eosinophils as dependent variables and the age as an explanatory variable in four GLMMs with a Poisson distribution (appropriate for the observed distribution of count data). Body mass at capture, sex, capture date, year of capture and the interactions between capture date and year of capture and between age and sex, were further included as fixed effects. Because individuals were sampled several times over the years, we included individual's identity as random intercepts (Table 1A). The functions "lmer" and "glmer" in the package "lme4" (Bates et al., 2015) were used to fit Linear Mixed Models (LMMs) and Generalized Linear Mixed Models (GLMMs) (Bolker et al., 2009). Models including linear, quadratic or no effect of age were considered and compared using Akaike's Information Criterion (AICc). The age effect models with the lowest AICc (Table S2) were selected. Afterwards, exploratory variables were removed following a backwards elimination procedure. The results obtained with the backwards elimination procedure were confirmed using an AICc selection (Table S3). We measured zero-inflation and variance inflation factors 
(VIFs) in all our models using the R package "performance" (Lüdecke et al., 2020). The only correlations between fixed effects we observed were between the body mass at capture and the year or the capture date as expected from the huge annual variability in body mass and the increase in body mass due to fat accumulation during the active season. For all models, we checked a posteriori the distribution of the residuals to assess the fit of the models to the observed data. Since we observed moderate overdispersion (all dispersion ratios $<$ 2.58 ) in some of our models (models for lymphocytes and neutrophils), we estimated all models' parameters using a Bayesian approach. From the final models, we used the "sim" function from the R-package "arm" to simulate values from the posterior distributions of the model parameters (Gelman \& Yu-Sung, 2020). The 95\% credible intervals (CI) around the mean were obtained after 5000 simulations. Assessment of statistical support was obtained from the posterior distribution of each parameter. We considered a fixed effect to be important if zero was not included within the $95 \%$ CI.

\section{Partitioned age effect}

To separate within- from between-individual variation with age, we tested for between- and within-individual age effect, using the same models as above but partitioning the age of each individual into 'average age' and 'delta age' (following van de Pol \& Wright, 2009)) (Table 1B). 'Average age' corresponds to the average of all ages at which an individual was sampled, and 'delta age' to the difference between its age at sampling and its 'average age'. The 'average age' represents the between-individual age effect, which corrects for the potential selective disappearance of individuals, while 'delta age' represents the within-individual age effect (van de Pol \& Wright, 2009). Models were selected using both a backwards elimination procedure and an information theoretic approach (see results in Table S4) and statistical support for parameters were estimated as above.

Finally, to test if the between- and within-individual age effects were significantly different, which would indicate selective (dis)appearance, we ran the five selected final models including both age and 'average age' as explanatory variables (Table 1C). In these models, 'age' represents the within-individual effect and 'average age' the difference between within- and between-individual effects (van de Pol \& Wright, 2009).

Immune phenotype and survival probability

We tested whether the death probability depended on leukocyte characteristics with mixed-effects Cox rightcensored regression models (Nenko et al., 2018; Ripatti \& Palmgren, 2000; Therneau et al., 2003). These models included leukocyte concentration or counts as time-dependent covariates and survival as response variable using the "coxme" function in the "coxme" R package (Therneau, 2018). The age at first capture and the sex were also included as fixed effects. Individual identity and year of birth were added as random effects to take into account repeated measurements and cohort effects (Table 2). The data were encoded with a zero as starting point for all individuals and with the years to death, to the end of the study, or to the next capture (for individuals with repeated data) as stop (Therneau, 2018). For the repeated data, the next interval started with the end of the previous interval. A ' 1 ' was assigned to the event variable, if the individual died during the interval. We assumed that an individual died if it was neither captured nor observed the following spring (monitored until 2018). A hazard ratio higher than one indicates that the corresponding explanatory variable is associated with an increased risk to die. All individuals were followed until death $(\mathrm{n}=27$ for leukocyte concentration and $\mathrm{n}=43$ for leukocyte counts) or still alive in $2018(\mathrm{n}=$

4 for leukocyte concentration and $n=6$ for leukocyte counts). Three individuals were excluded from this analysis because their fate (alive or dead) was uncertain, due to capture permit forbidding to monitor their families in 2017 and 2018.

\section{Results}

The lymphocyte and neutrophil counts, as well as the neutrophil and monocyte counts, were negatively correlated, while the monocyte and eosinophil counts were positively correlated (Table S1).

\section{Variations with age}


At the population level, for the leukocyte concentration, the best model was the model without age as explanatory variable, indicating that the leukocyte concentration did not vary with age (Table S2, 1A, Figure 1A). For the lymphocyte, neutrophil and eosinophil counts, the models with the quadratic age effect were better (Table S2). For the eosinophil counts, all the models with (linear and quadratic) and without age were competitive (Table S2). For the number of monocytes, the model with the linear age effect had the lowest AIC, but the model with the quadratic age effect was also probable (Table S2). The lymphocyte count decreased until 7 years old, followed by a slight increase at older ages (Figure 1B), conversely to neutrophil (Figure 1C) and eosinophil counts (Tables S2, 1A, Figure 1E). The monocyte count decreased with age (Tables S2, 1A, Figure 1D).

\section{Partitioned age effect}

Over the course of an individual's life, the lymphocyte count decreased with age (Figure 1B) while the neutrophil count increased (Table 1B, Figure 1C). Moreover, the difference between within- and betweenindividual effects was significant for both lymphocytes and neutrophils (significant average age terms in Table 1C), suggesting that individuals with a low lymphocyte and high neutrophil counts selectively disappeared from the sampled population (Figures 1B, 1C). The leukocyte concentration and the monocyte and eosinophil counts did not vary when an individual aged (Table 1B). We also found that males had less lymphocytes than females (Tables 1B, 1C).

\section{Immune phenotype and survival probability}

The individuals with a higher leukocyte concentration, lower lymphocyte counts, and higher neutrophils counts had a higher probability of death (Table 2). The monocyte or eosinophil counts did not affect death probability (Table 2 ).

\section{Discussion}

The immune phenotype of marmots varies with their age. While the leukocyte concentration remains stable over the course of an individual life, the lymphocyte count decreases, and the neutrophil count increases. In Mammals, lymphocytes and neutrophils make up the majority (80\%) of the leukocytes (Jain, 1993). Lymphocytes play a central role in acquired immunity, being involved in immunoglobulin and memory cell production and in the modulation of immune defence (Jain, 1993; Roitt et al., 2001; Vandervalk \& Herman, 1987). Involved in the innate immune response, neutrophils are the primary phagocytic leukocytes, and circulating phagocytes proliferate in response to infections, inflammation and stress (Jain, 1993).

A decrease in lymphocytes, together with an increase in neutrophils (Cheynel et al., 2017; Kirk et al., 2010), and more broadly, a decrease in the acquired immune system combined with an increase (or upkeep) in the innate immune system with age, was observed in various vertebrate species (reviewed in Peters et al., 2019). A decrease in the acquired immune system with age is often interpreted as a consequence of the thymus involution (Hakim \& Gress, 2007). The observed increase in neutrophil count does not necessarily mean a higher performance of the innate immune system with age. Indeed, the phagocytic ability of neutrophils could decrease with age (Gomez et al., 2008) and increasing their number could be an adaptive compensatory mechanism. However, this increase in neutrophil count could also be a compensation for a decrease in the efficacy of the acquired immunity. A remodeling of the immune system could indeed occur due to changes in the selective pressures when getting old. Given the lower probability to encounter new pathogens at old ages, downregulating the acquired immune system could be adaptive (Fulop et al., 2018). Immunosenescence should not be considered as a unidirectional deterioration, and would probably be better described by taking into account remodeling and reshaping of the immune functions with age (Fulop et al., 2018).

We observed less lymphocytes for marmot males than for females. Various hypotheses such as sex-differences in allocation strategy, intra-sexual competition (Metcalf \& Graham, 2018; Sheldon \& Verhulst, 1996) or inhibition of the immune system by some steroid hormones were often suggested to induce differences between males and females (Gubbels Bupp et al., 2018; Klein \& Flanagan, 2016; Taneja, 2018). However, we did not observe sex-specific differences in the variation of the immune phenotype with age. So far, studies of sex- 
specific patterns of immunosenescence remain equivocal: some suggested sex differences (e.g. (Gubbels Bupp et al., 2018; Tidière et al., 2020; van Lieshout et al., 2020; Bichet et al., submitted ), while others did not (e.g. Brooks \& Garratt, 2017; Cheynel et al., 2017; Kelly et al., 2018; Peters et al., 2019). For instance, van Lieshout et al. (2020) found a decrease in the proportion of lymphocytes with age in male badgers (Meles meles ), but not in females. The authors argued that this result could be explained by the high testosterone levels observed in male badgers, due to their polygynandrous mating system (Buesching et al., 2009), contrary to monogamous species (Sugianto et al., 2019) such as the Alpine marmot (Allainé, 2000; A. Cohas et al., 2006).

In our study, individuals with fewer lymphocytes but more neutrophils were more likely to die. This result was further confirmed by a significant selective disappearance of individuals with this phenotype. Innate cellular response (involving neutrophils) is considered as costly in terms of energy and autoimmune damage (Lee, 2006). Individuals with neutrophil-oriented response may be unable to mount an appropriate immune response against challenges encountered at old ages (Froy et al., 2019), and/or may have an excessive cost to this response and die.

Our study also illustrates the importance of longitudinal analyses and the use of appropriate statistical tools to avoid misleading conclusions regarding immunosenescence (Peters et al., 2019; van de Pol \& Wright, 2009). At the population level, our analyses revealed quadratic age effects on immune parameters, probably due to a combination of variations in the strength of selective disappearance with age and of within-individual variations (Figure 1). Our current knowledge derived from cross-sectional studies thus has to be taken with caution (Peters et al., 2019). So far, only three studies investigated longitudinal variations with age in the immune functions (Beirne et al., 2016; Andrea L. Graham et al., 2010; Schneeberger et al., 2014) which is clearly not enough to understand senescence in a complex system like immunity. For instance, in the Greater Sac-Winged Bat (Saccopteryx bilineata), it was found that the number of leukocytes decreased with age, both within and between individuals, while the immunoglobulin G concentration was higher in older individuals, but did not vary within individuals, and the bacterial killing capacity of the plasma did not vary with age, at both levels (Schneeberger et al., 2014). These variations with age also impacted the short-term survival probability (Schneeberger et al., 2014). More longitudinal studies, like the present one, are highly necessary to properly understand the patterns and consequences of immunosenescence for wild individuals and populations.

\section{Data Accessibility}

Data are available from the Dryad Digital Repository upon acceptance.

\section{Competing Interests}

The authors declare that they have no conflict of interest.

\section{Author Contributions}

C.B., E.G.-F. and A.C. designed the study; A.C. collected blood samples; C.R. and E.G.-F. did the laboratory work; C.B. analysed the data; C.B. and A.C. wrote the paper with contributions from all authors.

\section{Acknowledgements}

We thank all the volunteers involved in marmot catching. We thank O. Vedder and S. Bouwhuis for their helpful comments and F. Kirkpatrick Baird for editing this manuscript. We also warmly thank M. Moiron for her advices regarding statistical analyses. The ANR-13-JSV7-0005 supported this work. The protocol was conducted under the permit AP n82010/121 and approved by the national ethical committee (n8BH2012-92 V1). The last author is authorised for animal experimentation (n8R45GRETAF110). The authors declare to have no conflict of interest.

\section{References}

Abolins, S., Lazarou, L., Weldon, L., Hughes, L., King, E. C., Drescher, P., Pocock, M. J. O., Hafalla, J. 
C. R., Riley, E. M., \& Viney, M. (2018). The ecology of immune state in a wild mammal, Mus musculus domesticus.Plos Biology , 16 (4), e2003538. https://doi.org/10.1371/journal.pbio.2003538

Akira, S., Uematsu, S., \& Takeuchi, O. (2006). Pathogen recognition and innate immunity. Cell , 124 (4), 783-801. https://doi.org/10.1016/j.cell.2006.02.015

Allainé, D. (2000). Sociality, mating system and reproductive skew in marmots: Evidence and hypotheses. Behavioural Processes ,51 (1-3), 21-34. https://doi.org/10.1016/s0376-6357(00)00116-9

Arnold, W., \& Dittami, J. (1997). Reproductive suppression in male alpine marmots. Animal Behaviour , 53 , 53-66. https://doi.org/10.1006/anbe.1996.0277

Bates, D., Maechler, M., Bolker, B. M., \& Walker, S. C. (2015). Fitting Linear Mixed-Effects Models Using lme4. Journal of Statistical Software, 67 (1), 1-48.

Bauer, M. E., \& De la Fuente, M. (2016). The role of oxidative and inflammatory stress and persistent viral infections in immunosenescence.Mechanisms of Ageing and Development , 158 , 27-37. https://doi.org/10.1016/j.mad.2016.01.001

Beirne, C., Waring, L., McDonald, R. A., Delahay, R., \& Young, A. (2016). Age-related declines in immune response in a wild mammal are unrelated to immune cell telomere length. Proceedings of the Royal Society B-Biological Sciences , 283 (1825), 20152949. https://doi.org/10.1098/rspb.2015.2949

Bektas, A., Schurman, S. H., Sen, R., \& Ferrucci, L. (2017). Human T cell immunosenescence and inflammation in aging. Journal of Leukocyte Biology , 102 (4), 977-988. https://doi.org/10.1189/jlb.3RI0716-335R

Bolker, B. M., Brooks, M. E., Clark, C. J., Geange, S. W., Poulsen, J. R., Stevens, M. H. H., \& White, J.-S. S. (2009). Generalized linear mixed models: A practical guide for ecology and evolution. Trends in Ecology E Evolution, 24 (3), 127-135. https://doi.org/10.1016/j.tree.2008.10.008

Boughton, R. K., Joop, G., \& Armitage, S. A. O. (2011). Outdoor immunology: Methodological considerations for ecologists.Functional Ecology , 25 (1), 81-100. https://doi.org/10.1111/j.1365-2435.2010.01817.x

Brooks, R. C., \& Garratt, M. G. (2017). Life history evolution, reproduction, and the origins of sexdependent aging and longevity.Annals of the New York Academy of Sciences , 1389 (1), 92-107. https://doi.org/10.1111/nyas.13302

Buesching, C. D., Heistermann, M., \& Macdonald, D. W. (2009). Seasonal and inter-individual variation in testosterone levels in badgers Meles meles: Evidence for the existence of two endocrinological phenotypes. Journal of Comparative Physiology A , 195 (9), 865-871. https://doi.org/10.1007/s00359-009-0465-0

Cheynel, L., Lemaitre, J.-F., Gaillard, J.-M., Rey, B., Bourgoin, G., Ferte, H., Jego, M., Debias, F., Pellerin, M., Jacob, L., \& Gilot-Fromont, E. (2017). Immunosenescence patterns differ between populations but not between sexes in a long-lived mammal.Scientific Reports , 7 , 13700. https://doi.org/10.1038/s41598-017$13686-5$

Cohas, A., Yoccoz, N. G., Silva, A. D., Goossens, B., \& Allainé, D. (2006). Extra-Pair Paternity in the Monogamous Alpine Marmot (Marmota marmota): The Roles of Social Setting and Female Mate Choice. Behavioral Ecology and Sociobiology , 59 (5), 597-605. JSTOR.

Cohas, A., Yoccoz, N. G., Bonenfant, C., Goossens, B., Genton, C., Galan, M., Kempenaers, B., \& Allainé, D. (2008). The genetic similarity between pair members influences the frequency of extrapair paternity in alpine marmots. Animal Behaviour , 76 (1), 87-95. https://doi.org/10.1016/j.anbehav.2008.01.012

Demas, G. E., Zysling, D. A., Beechler, B. R., Muehlenbein, M. P., \& French, S. S. (2011). Beyond phytohaemagglutinin: Assessing vertebrate immune function across ecological contexts. Journal of Animal Ecology , 80 (4), 710-730. https://doi.org/10.1111/j.1365-2656.2011.01813.x 
Eraud, C., Jacquet, A., \& Faivre, B. (2009). Survival Cost of an Early Immune Soliciting in Nature. Evolution , 63 (4), 1036-1043. https://doi.org/10.1111/j.1558-5646.2008.00540.x

Franceschi, C., Capri, M., Monti, D., Giunta, S., Olivieri, F., Sevini, F., Panourgia, M. P., Invidia, L., Celani, L., Scurti, M., Cevenini, E., Castellani, G. C., \& Salvioli, S. (2007). Inflammaging and anti-inflammaging: A systemic perspective on aging and longevity emerged from studies in humans. Mechanisms of Ageing and Development ,128 (1), 92-105. https://doi.org/10.1016/j.mad.2006.11.016

Franceschi, C., Garagnani, P., Parini, P., Giuliani, C., \& Santoro, A. (2018). Inflammaging: A new immune-metabolic viewpoint for age-related diseases. Nature Reviews Endocrinology , 14 (10), 576-590. https://doi.org/10.1038/s41574-018-0059-4

Frasca, D., Riley, R. L., \& Blomberg, B. B. (2005). Humoral immune response and B-cell functions including immunoglobulin class switch are downregulated in aged mice and humans. Seminars in Immunology ,17 (5), 378-384. https://doi.org/10.1016/j.smim.2005.05.005

Frasca, D., Diaz, A., Romero, M., Landin, A. M., \& Blomberg, B. B. (2011). Age effects on B cells and humoral immunity in humans.Ageing Research Reviews , 10 (3), 330-335. https://doi.org/10.1016/j.arr.2010.08.004

Froy, H., Sparks, A. M., Watt, K., Sinclair, R., Bach, F., Pilkington, J. G., Pemberton, J. M., McNeilly, T. N., \& Nussey, D. H. (2019). Senescence in immunity against helminth parasites predicts adult mortality in a wild mammal. Science, 365 (6459), 1296-1298. https://doi.org/10.1126/science.aaw5822

Fulop, T., Larbi, A., Dupuis, G., Le Page, A., Frost, E. H., Cohen, A. A., Witkowski, J. M., \& Franceschi, C. (2018). Immunosenescence and Inflamm-Aging As Two Sides of the Same Coin: Friends or Foes? Frontiers in Immunology , 8 , 1960. https://doi.org/10.3389/fimmu.2017.01960

Gayoso, I., Sanchez-Correa, B., Campos, C., Alonso, C., Pera, A., Casado, J. G., Morgado, S., Tarazona, R., \& Solana, R. (2011). Immunosenescence of Human Natural Killer Cells. Journal of Innate Immunity , 3 (4), 337-343. https://doi.org/10.1159/000328005

Gelman, A., \& Yu-Sung. (2020). arm: Data Analysis Using Regression and Multilevel/Hierarchical Models (1.11-2) [Computer software]. https://CRAN.R-project.org/package=arm

Gomez, C. R., Nomellini, V., Faunce, D. E., \& Kovacs, E. J. (2008). Innate immunity and aging. Experimental Gerontology ,43 (8), 718-728. https://doi.org/10.1016/j.exger.2008.05.016

Goto, M. (2008). Inflammaging (inflammation plus aging): A driving force for human aging based on an evolutionarily antagonistic pleiotropy theory? Bioscience Trends , 2 (6), 218-230.

Graham, A. L., Allen, J. E., \& Read, A. F. (2005). Evolutionary causes and consequences of immunopathology. In Annual Review of Ecology Evolution and Systematics (Vol. 36, pp. 373-397). Annual Reviews.

Graham, A. L., Hayward, A. D., Watt, K. A., Pilkington, J. G., Pemberton, J. M., \& Nussey, D. H. (2010). Fitness Correlates of Heritable Variation in Antibody Responsiveness in a Wild Mammal.Science , 330 (6004), 662-665. https://doi.org/10.1126/science.1194878

Gubbels Bupp, M. R., Potluri, T., Fink, A. L., \& Klein, S. L. (2018). The Confluence of Sex Hormones and Aging on Immunity. Frontiers in Immunology , 9 , 1269. https://doi.org/10.3389/fimmu.2018.01269

Hacklander, K., Mostl, E., \& Arnold, W. (2003). Reproductive suppression in female Alpine marmots, Marmota marmota. Animal Behaviour , 65 , 1133-1140. https://doi.org/10.1006/anbe.2003.2159

Hakim, F. T., \& Gress, R. E. (2007). Immunosenescence: Deficits in adaptive immunity in the elderly. Tissue Antigens , 70 (3), 179-189. https://doi.org/10.1111/j.1399-0039.2007.00891.x

Hamilton, W. (1966). Moulding of Senescence by Natural Selection. Journal of Theoretical Biology , 12 (1), 12-. https://doi.org/10.1016/0022-5193(66)90184-6 
Hanssen, S. A., Hasselquist, D., Folstad, I., \& Erikstad, K. E. (2004). Costs of immunity: Immune responsiveness reduces survival in a vertebrate. Proceedings of the Royal Society B-Biological Sciences , 271 (1542), 925-930. https://doi.org/10.1098/rspb.2004.2678

Hawkey, C. M., \& Dennett, T. B. (1989). A colour atlas of comparative veterinary haematology. Normal and abnormal blood cells in mammals, birds and reptiles. Wolfe Publishing Limited, Ipswich.

Hill, S. C., Manvell, R. J., Schulenburg, B., Shell, W., Wikramaratna, P. S., Perrins, C., Sheldon, B. C., Brown, I. H., \& Pybus, O. G. (2016). Antibody responses to avian influenza viruses in wild birds broaden with age. Proceedings of the Royal Society B-Biological Sciences , 283 (1845), 20162159. https://doi.org/10.1098/rspb.2016.2159

Hoebe, K., Janssen, E., \& Beutler, B. (2004). The interface between innate and adaptive immunity. Nature Immunology , 5 (10), 971-974. https://doi.org/10.1038/ni1004-971

Iwasaki, A., \& Medzhitov, R. (2010). Regulation of Adaptive Immunity by the Innate Immune System. Science, 327 (5963), 291-295. https://doi.org/10.1126/science.1183021

Jain, N. C. (1993). Essentials of Veterinary Hematology . Blackwell Publishing.

Kelly, C. D., Stoehr, A. M., Nunn, C., Smyth, K. N., \& Prokop, Z. M. (2018). Sexual dimorphism in immunity across animals: A meta-analysis . https://pubag.nal.usda.gov/catalog/6206256

Kirk, C. M., Amstrup, S., Swor, R., Holcomb, D., \& O'Hara, T. M. (2010). Hematology of Southern Beaufort Sea Polar Bears (2005-2007): Biomarker for an Arctic Ecosystem Health Sentinel. Ecohealth ,7 (3), 307-320. https://doi.org/10.1007/s10393-010-0322-1

Klein, S. L., \& Flanagan, K. L. (2016). Sex differences in immune responses. Nature Reviews. Immunology , 16 (10), 626-638. https://doi.org/10.1038/nri.2016.90

Larbi, A., Franceschi, C., Mazzatti, D., Solana, R., Wikby, A., \& Pawelec, G. (2008). Aging of the immune system as a prognostic factor for human longevity. Physiology , 23 (2), 64-74. https://doi.org/10.1152/physiol.00040.2007

Lardy, S., Cohas, A., Desouhant, E., Tafani, M., \& Allaine, D. (2012). Paternity and Dominance Loss in Male Breeders: The Cost of Helpers in a Cooperatively Breeding Mammal. PLoS ONE , 7 (1), e29508. https://doi.org/10.1371/journal.pone.0029508

Lardy, S., Cohas, A., Figueroa, I., \& Allaine, D. (2011). Mate change in a socially monogamous mammal: Evidences support the "forced divorce" hypothesis. Behavioral Ecology , 22 (1), 120-125. https://doi.org/10.1093/beheco/arq168

Lavoie, E. T. (2006). Avian immunosenescence. AGE , 27 (4), 281-285. https://doi.org/10.1007/s11357005-4561-y

Lecomte, V. J., Sorci, G., Cornet, S., Jaeger, A., Faivre, B., Arnoux, E., Gaillard, M., Trouve, C., Besson, D., Chastel, O., \& Weimerskirch, H. (2010). Patterns of aging in the long-lived wandering albatross.Proceedings of the National Academy of Sciences of the United States of America, 107 (14), 6370-6375. https://doi.org/10.1073/pnas.0911181107

Lee, K. A. (2006). Linking immune defenses and life history at the levels of the individual and the species. Integrative and Comparative Biology , 46 (6), 1000-1015. https://doi.org/10.1093/icb/icl049

Lemaitre, J.-F., Berger, V., Bonenfant, C., Douhard, M., Gamelon, M., Plard, F., \& Gaillard, J.-M. (2015). Early-late life trade-offs and the evolution of ageing in the wild. Proceedings of the Royal Society B-Biological Sciences , 282 (1806), UNSP 20150209. https://doi.org/10.1098/rspb.2015.0209

Lochmiller, R. L., \& Deerenberg, C. (2000). Trade-offs in evolutionary immunology: Just what is the cost of immunity? Oikos ,88 (1), 87-98. https://doi.org/10.1034/j.1600-0706.2000.880110.x 
Ludecke, D., Makowski, D., Waggoner, P., \& Patil, I. (2020).performance: Assessment of Regression Models Performance . https://easystats.github.io/performance/

Maizels, R. M., \& Nussey, D. H. (2013). Into the wild: Digging at immunology's evolutionary roots. Nature Immunology , 14, 879-883. https://doi.org/10.1038/ni.2643

Mantovani, A., Cassatella, M. A., Costantini, C., \& Jaillon, S. (2011). Neutrophils in the activation and regulation of innate and adaptive immunity. Nature Reviews. Immunology , 11 (8), 519-531. https://doi.org/10.1038/nri3024

Massot, M., Clobert, J., Montes-Poloni, L., Haussy, C., Cubo, J., \& Meylan, S. (2011). An integrative study of ageing in a wild population of common lizards. Functional Ecology , 25 (4), 848-858. https://doi.org/10.1111/j.1365-2435.2011.01837.x

Metcalf, C. J. E., \& Graham, A. L. (2018). Schedule and magnitude of reproductive investment under immune trade-offs explains sex differences in immunity. Nature Communications , 9 (1), 4391. https://doi.org/10.1038/s41467-018-06793-y

Mueller, L., Fueloep, T., \& Pawelec, G. (2013). Immunosenescence in vertebrates and invertebrates. Immunity \& Ageing , 10 , 12. https://doi.org/10.1186/1742-4933-10-12

Nathan, C. (2006). Neutrophils and immunity: Challenges and opportunities. Nature Reviews. Immunology , 6 (3), 173-182. https://doi.org/10.1038/nri1785

Nenko, I., Hayward, A. D., Simons, M. J. P., \& Lummaa, V. (2018). Early-life environment and differences in costs of reproduction in a preindustrial human population. Plos One, 13 (12), e0207236. https://doi.org/10.1371/journal.pone.0207236

Nikolich-Zugich, J. (2018). The twilight of immunity: Emerging concepts in aging of the immune system. Nature Immunology , 19 (1), 10-19. https://doi.org/10.1038/s41590-017-0006-x

Noreen, E., Bourgeon, S., \& Bech, C. (2011). Growing old with the immune system: A study of immunosenescence in the zebra finch (Taeniopygia guttata). Journal of Comparative Physiology B-Biochemical Systemic and Environmental Physiology , 181 (5), 649-656. https://doi.org/10.1007/s00360-011-0553-7

Nussey, D. H., Coulson, T., Festa-Bianchet, M., \& Gaillard, J.-M. (2008). Measuring senescence in wild animal populations: Towards a longitudinal approach. Functional Ecology , 22 (3), 393-406. https://doi.org/10.1111/j.1365-2435.2008.01408.x

Nussey, D. H., Watt, K., Pilkington, J. G., Zamoyska, R., \& McNeilly, T. N. (2012). Age-related variation in immunity in a wild mammal population. Aging Cell , 11 (1), 178-180. https://doi.org/10.1111/j.14749726.2011.00771.x

Palacios, M. G., Cunnick, J. E., Winkler, D. W., \& Vleck, C. M. (2007). Immunosenescence in some but not all immune components in a free-living vertebrate, the tree swallow. Proceedings of the Royal Society B-Biological Sciences , 274 (1612), 951-957. https://doi.org/10.1098/rspb.2006.0192

Panda, A., Arjona, A., Sapey, E., Bai, F., Fikrig, E., Montgomery, R. R., Lord, J. M., \& Shaw, A. C. (2009). Human innate immunosenescence: Causes and consequences for immunity in old age. Trends in Immunology , 30 (7), 325-333. https://doi.org/10.1016/j.it.2009.05.004

Peters, A., Delhey, K., Nakagawa, S., Aulsebrook, A., \& Verhulst, S. (2019). Immunosenescence in wild animals: Meta-analysis and outlook.Ecology Letters, 22 (10), 1709-1722. https://doi.org/10.1111/ele.13343

R Core Team. (2014). R: A language and environment for statistical computing . R Foundation for Statistical Computing. http://www.R-project.org/

Ripatti, S., \& Palmgren, J. (2000). Estimation of multivariate frailty models using penalized partial likelihood. Biometrics ,56 (4), 1016-1022. https://doi.org/10.1111/j.0006-341X.2000.01016.x 
Roitt, I., Brostoff, J., \& Male, D. (2001). Immunology . Mosby-Harcourt Publishers.

Saino, N., Ferrari, R. P., Romano, M., Rubolini, D., \& Moller, A. P. (2003). Humoral immune response in relation to senescence, sex and sexual ornamentation in the barn swallow (Hirundo rustica). Journal of Evolutionary Biology , 16 (6), 1127-1134. https://doi.org/10.1046/j.1420-9101.2003.00616.x

Schneeberger, K., Courtiol, A., Czirjak, G. A., \& Voigt, C. C. (2014). Immune Profile Predicts Survival and Reflects Senescence in a Small, Long-Lived Mammal, the Greater Sac-Winged Bat (Saccopteryx bilineata ). Plos One , 9 (9), e108268. https://doi.org/10.1371/journal.pone.0108268

Shanley, D. P., Aw, D., Manley, N. R., \& Palmer, D. B. (2009). An evolutionary perspective on the mechanisms of immunosenescence.Trends in Immunology , 30 (7), 374-381. https://doi.org/10.1016/j.it.2009.05.001

Shaw, A. C., Goldstein, D. R., \& Montgomery, R. R. (2013). Age-dependent dysregulation of innate immunity. Nature Reviews Immunology , 13 (12), 875-887. https://doi.org/10.1038/nri3547

Sheldon, B. C., \& Verhulst, S. (1996). Ecological immunology: Costly parasite defences and trade-offs in evolutionary ecology. Trends in Ecology 83 Evolution , 11 (8), 317-321. https://doi.org/10.1016/0169$5347(96) 10039-2$

Simon, A. K., Hollander, G. A., \& McMichael, A. (2015). Evolution of the immune system in humans from infancy to old age. Proceedings of the Royal Society B-Biological Sciences , 282 (1821), 20143085. https://doi.org/10.1098/rspb.2014.3085

Solana, R., Tarazona, R., Gayoso, I., Lesur, O., Dupuis, G., \& Fulop, T. (2012). Innate immunosenescence: Effect of aging on cells and receptors of the innate immune system in humans. Seminars in Immunology , 24 (5), 331-341. https://doi.org/10.1016/j.smim.2012.04.008

Sugianto, N. A., Newman, C., Macdonald, D. W., \& Buesching, C. D. (2019). Heterochrony of puberty in the European badger (Meles meles) can be explained by growth rate and group-size: Evidence for two endocrinological phenotypes. PLOS ONE , 14 (3), e0203910. https://doi.org/10.1371/journal.pone.0203910

Taneja, V. (2018). Sex Hormones Determine Immune Response.Frontiers in Immunology , 9. https://doi.org/10.3389/fimmu.2018.01931

Therneau, T. M. (2018). coxme: Mixed Effects Cox Models . https://CRAN.R-project.org/package=coxme

Therneau, T. M., Grambsch, P. M., \& Pankratz, V. S. (2003). Penalized survival models and frailty. Journal of Computational and Graphical Statistics , 12 (1), 156-175. https://doi.org/10.1198/1061860031365

Tidiere, M., Badruna, A., Fouchet, D., Gaillard, J.-M., Lemaitre, J.-F., \& Pontier, D. (2020). Pathogens Shape Sex Differences in Mammalian Aging. Trends in Parasitology , 36 (8), 668-676. https://doi.org/10.1016/j.pt.2020.05.004

Ujvari, B., \& Madsen, T. (2011). Do natural antibodies compensate for humoral immunosenescence in tropical pythons? Functional Ecology ,25 (4), 813-817. https://doi.org/10.1111/j.1365-2435.2011.01860.x

van de Pol, M., \& Verhulst, S. (2006). Age-dependent traits: A new statistical model to separate withinand between-individual effects. The American Naturalist , 167 (5), 766-773. https://doi.org/10.1086/503331

van de Pol, M., \& Wright, J. (2009). A simple method for distinguishing within- versus between-subject effects using mixed models. Animal Behaviour , 77 (3), 753-758. https://doi.org/10.1016/j.anbehav.2008.11.006

van Lieshout, S. H. J., Badas, E. P., Mason, M. W. T., Newman, C., Buesching, C. D., Macdonald, D. W., \& Dugdale, H. L. (2020). Social effects on age-related and sex-specific immune cell profiles in a wild mammal. Biology Letters , 16 (7), 20200234. https://doi.org/10.1098/rsbl.2020.0234

Vandervalk, P., \& Herman, C. J. (1987). Leukocyte functions.Laboratory Investigation , 56 , 127-137. 
Vermeulen, A., Eens, M., Van Dongen, S., \& Muller, W. (2017). Does baseline innate immunity change with age? A multi-year study in great tits. Experimental Gerontology , 92 , 67-73. https://doi.org/10.1016/j.exger.2017.03.011

Viney, M. E., Riley, E. M., \& Buchanan, K. L. (2005). Optimal immune responses: Immunocompetence revisited. Trends in Ecology \& Evolution, 20 (12), 665-669. https://doi.org/10.1016/j.tree.2005.10.003

Vivier, E., Raulet, D. H., Moretta, A., Caligiuri, M. A., Zitvogel, L., Lanier, L. L., Yokoyama, W. M., \& Ugolini, S. (2011). Innate or adaptive immunity? The example of natural killer cells. Science (New York, N.Y.) , 331 (6013), 44-49. https://doi.org/10.1126/science.1198687

Zimmerman, L. M., Clairardin, S. G., Paitz, R. T., Hicke, J. W., LaMagdeleine, K. A., Vogel, L. A., \& Bowden, R. M. (2013). Humoral immune responses are maintained with age in a long-lived ectotherm, the redeared slider turtle. Journal of Experimental Biology,216 (4), 633-640. https://doi.org/10.1242/jeb.078832

\section{Tables}

Table 1: Parameter estimates and confidence intervals at 95\% (CI) for the selected (A) age models, (B) models separating within- and between-individual effects, and (C) models testing the differences between within- and between-individual variations with age describing the immune phenotype. Parameters were obtained from the minimal adequate models. Significant effects (CI which do not overlapped zero) are in bold. "- " means a parameter not retained in the model.

\begin{tabular}{lllll}
\hline A. Age models & & & & \\
\hline Dependent variable & Leukocyte concentration* & Leukocyte concentration* & Lymphocyte count** & Lymphoc \\
Fixed effects & Estimate & $95 \%$ CI & Estimate & Estimate \\
Intercept & $\mathbf{1 6 . 6 6}$ & $\mathbf{1 6 . 4 4 1 , \mathbf { 1 6 . 8 7 9 }}$ & $\mathbf{3 . 3 9}$ & $\mathbf{3 . 3 9}$ \\
Age & & $\mathbf{- 0 . 1 7}$ & $\mathbf{- 0 . 1 7}$ \\
Age & & & $\mathbf{0 . 1 2}$ & $\mathbf{0 . 1 2}$ \\
Sex (male) & -0.09 & $-0.303,0.121$ & -0.20 & -0.20 \\
Body mass & -0.03 & $-0.150,0.095$ & $\mathbf{0 . 1 4}$ & $\mathbf{0 . 1 4}$ \\
Date & 0.06 & $-0.082,0.196$ & $\mathbf{0 . 0 9}$ & $\mathbf{0 . 0 9}$ \\
Year (2012) & & & -0.04 & -0.04 \\
Year (2013) & & & $\mathbf{0 . 1 9}$ & $\mathbf{0 . 1 9}$ \\
Year (2014) & $\mathbf{0 . 3 2}$ & $\mathbf{0 . 0 5 7 , 0 . 5 6 4}$ & -0.04 & -0.04 \\
Year (2015) & 0.23 & $-0.013,0.475$ & -0.12 & -0.12 \\
Date:year (2012) & & & $-\mathbf{0 . 2 7}$ & $\mathbf{- 0 . 2 7}$ \\
Date:year (2013) & & - & -0.20 & -0.20 \\
Date:year (2014) & - & - & -0.07 & -0.07 \\
Date:year (2015) & - & -0.07 & -0.07 \\
Random ID & $\mathbf{0 . 0 3}$ & $\mathbf{0 . 0 1 7 , 0 . 0 4 7}$ & $\mathbf{0 . 1 3}$ \\
\hline
\end{tabular}

\begin{tabular}{ll}
\hline B. Models separating within- and between-individual effects & B. Models separating within- and between-in \\
\hline Dependant variable & Leukocyte concentration* \\
Fixed effects & Estimate \\
Intercept & $\mathbf{1 6 . 5 1}$ \\
Average age & -0.06 \\
Delta age & -0.40 \\
Sex (male) & -0.09 \\
Body mass & -0.05 \\
Date & 0.06
\end{tabular}


B. Models separating within- and between-individual effects

Year (2012)

Year (2013)

Year (2014)

Year (2015)

Date:year 2012

Date:year 2013

Date:year 2014

Date:year 2015

Random ID
B. Models separating within- and between-in

0.44

0.49

0.03

\begin{tabular}{lc}
\hline C. Models testing the differences between within- and between-individual variations with age & C. Models t \\
\hline Dependant variable & Leukocyte c \\
Fixed effects & Estimate \\
Intercept & $\mathbf{1 6 . 5 2}$ \\
Age & -0.40 \\
Average age & 0.34 \\
Sex (male) & -0.09 \\
Body mass & -0.05 \\
Date & 0.06 \\
Year (2012) & \\
Year (2013) & $\mathbf{0 . 4 4}$ \\
Year (2014) & 0.49 \\
Year (2015) & \\
Date:year (2012) & - \\
Date:year (2013) & - \\
Date:year (2014) & $-\mathbf{0 3}$ \\
Date:year (2015) & $\mathbf{0 . 0 3}$ \\
Random ID &
\end{tabular}

*Between 2013 and 2015, the leukocyte concentration was determined for 79 samples from 34 individuals sampled between two and three times. 23 individuals had two samples in different years and 11 individuals had three.

**Between 2011 and 2015, the leukocyte counts were determined for 169 blood smears from 52 individuals sampled between two and five times. 18 individuals had two samples in different years, 12 had three, 13 had four, and 9 individuals had five. 33 individuals were both measured for leukocyte concentration and leukocyte counts (which corresponds to 75 measurements).

Table 2: Associations between immune phenotype and the probability of mortality. Significant effects are in bold. 


\begin{tabular}{|c|c|c|c|c|c|c|c|c|c|c|c|c|c|c|c|}
\hline $\begin{array}{l}\text { ime- } \\
\text { epende }\end{array}$ & $\begin{array}{l}\text { Leukod } \\
\text { con- } \\
\text { cen- } \\
\text { tra- } \\
\text { tion } \\
(\mathrm{N}= \\
72, \mathrm{n} \\
\text { ent } 27 \\
\text { tevents })\end{array}$ & $\begin{array}{l}\text { con- } \\
\text { cen- } \\
\text { tra- } \\
\text { tion } \\
(\mathrm{N}= \\
72, \mathrm{n} \\
=27 \\
\text { events })\end{array}$ & $\begin{array}{l}\text { con- } \\
\text { cen- } \\
\text { tra- } \\
\text { tion } \\
(\mathrm{N}= \\
72, \mathrm{n} \\
=27 \\
\text { events })\end{array}$ & $\begin{array}{l}\text { Lymph } \\
\text { count } \\
(\mathrm{N}= \\
163, \\
\mathrm{n}= \\
43 \\
\text { events) }\end{array}$ & $\begin{array}{l}\text { count } \\
(\mathrm{N}= \\
163, \\
\mathrm{n}= \\
43 \\
\text { events) }\end{array}$ & $\begin{array}{l}\text { hळgyth甲h } \\
\text { count } \\
(\mathrm{N}= \\
163, \\
\mathrm{n}= \\
43 \\
\text { events) }\end{array}$ & $\begin{array}{l}\text { holgyttro } \\
\text { count } \\
(\mathrm{N}= \\
163, \\
\mathrm{n}= \\
43 \\
\text { events) }\end{array}$ & $\begin{array}{l}\text { opleiihtrc } \\
\text { count } \\
(\mathrm{N}= \\
163, \\
\mathrm{n}= \\
43 \\
\text { events) }\end{array}$ & $\begin{array}{l}\text { opleihtro } \\
\text { count } \\
(\mathrm{N}= \\
163, \\
\mathrm{n}= \\
43 \\
\text { events })\end{array}$ & $\begin{array}{l}\text { opleihtro } \\
\text { count } \\
(\mathrm{N}= \\
163, \\
\mathrm{n}= \\
43 \\
\text { events) }\end{array}$ & $\begin{array}{l}\text { ophohoc } \\
\text { count } \\
(\mathrm{N}= \\
163, \\
\mathrm{n}= \\
43 \\
\text { events) }\end{array}$ & $\begin{array}{l}\text { cyttenoc } \\
\text { count } \\
(\mathrm{N}= \\
163, \\
\mathrm{n}= \\
43 \\
\text { events })\end{array}$ & $\begin{array}{l}\text { coltenoc } \\
\text { count } \\
(\mathrm{N}= \\
163, \\
\mathrm{n}= \\
43 \\
\text { events })\end{array}$ & $\begin{array}{l}\text { cyttenoc } \\
\text { count } \\
(\mathrm{N}= \\
163 \\
\mathrm{n}= \\
43 \\
\text { events })\end{array}$ & \\
\hline & $\begin{array}{l}\text { Hazarc } \\
\text { ra- } \\
\text { tio } \\
\pm \\
\mathrm{SE}\end{array}$ & $\begin{array}{l}\mathrm{Z} \\
\text { value }\end{array}$ & $\begin{array}{l}\mathrm{p}- \\
\text { value }\end{array}$ & $\begin{array}{l}\text { Hazard } \\
\text { ra- } \\
\text { tio } \\
\pm \\
\mathrm{SE}\end{array}$ & $\begin{array}{l}\mathrm{Z} \\
\text { value }\end{array}$ & $\begin{array}{l}\mathrm{p}- \\
\text { value }\end{array}$ & $\begin{array}{l}\mathrm{p}- \\
\text { value }\end{array}$ & $\begin{array}{l}\text { Hazard } \\
\text { ra- } \\
\text { tio } \\
\pm \\
\mathrm{SE}\end{array}$ & $\begin{array}{l}\mathrm{Z} \\
\text { value }\end{array}$ & $\begin{array}{l}\mathrm{p}- \\
\text { value }\end{array}$ & $\begin{array}{l}\mathrm{p}- \\
\text { value }\end{array}$ & $\begin{array}{l}\text { Hazard } \\
\text { ra- } \\
\text { tio } \\
\pm \\
\mathrm{SE}\end{array}$ & $\begin{array}{l}\mathrm{Z} \\
\text { value }\end{array}$ & $\begin{array}{l}\mathrm{p}- \\
\text { value }\end{array}$ & \\
\hline $\begin{array}{l}\text { Leukocy } \\
\text { variable }\end{array}$ & $\begin{array}{l}y \mathbf{1} e 00 \\
e \pm \\
0.00\end{array}$ & $1.9^{\prime}$ & 0.049 & $\begin{array}{l}0.96 \\
\pm \\
0.01\end{array}$ & $-\overline{3.00}$ & 0.003 & 0.003 & $\begin{array}{l}1.03 \\
\pm \\
0.01\end{array}$ & 280 & 0.005 & 0.005 & $\begin{array}{l}0.93 \\
\pm \\
0.07\end{array}$ & $\begin{array}{l}- \\
1.02\end{array}$ & .310 & \\
\hline $\begin{array}{l}\text { Age } \\
\text { at } \\
\text { first } \\
\text { capture }\end{array}$ & $\begin{array}{l}1.31 \\
\pm \\
0.10\end{array}$ & 2.68 & 0.007 & $\begin{array}{l}1.11 \\
\pm \\
0.09\end{array}$ & 1.21 & 0.230 & 0.230 & $\begin{array}{l}1.12 \\
\pm \\
0.09\end{array}$ & 1.30 & 0.190 & 0.190 & $\begin{array}{l}1.07 \\
\pm \\
0.09\end{array}$ & 0.78 & .440 & \\
\hline $\begin{array}{l}\text { Sex } \\
\text { (male) }\end{array}$ & $\begin{array}{l}0.98 \\
\pm \\
0.40\end{array}$ & $\begin{array}{l}- \\
0.04\end{array}$ & 0.970 & $\begin{array}{l}- \\
0.53 \\
\pm \\
0.33\end{array}$ & $\begin{array}{l}- \\
1.90\end{array}$ & 0.058 & 0.058 & $\begin{array}{l}0.61 \\
\pm \\
0.33\end{array}$ & $\begin{array}{l}- \\
1.54\end{array}$ & 0.120 & 0.120 & $\begin{array}{l}0.72 \\
\pm \\
0.32\end{array}$ & $\begin{array}{l}- \\
1.02\end{array}$ & 0.310 & \\
\hline
\end{tabular}

Figure legends 

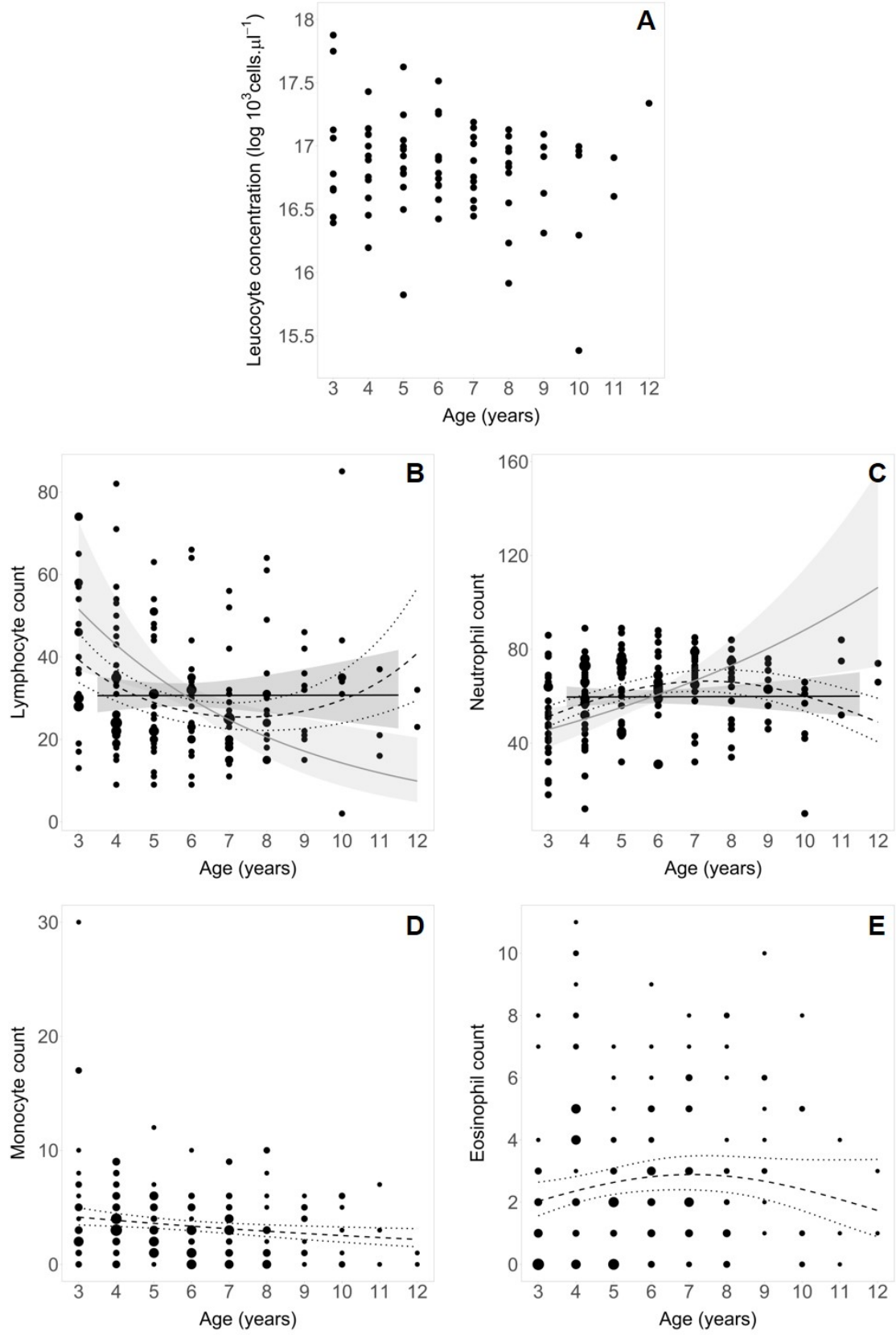

Figure 1: Age-specific variation of (A) leukocyte concentration and counts of (B) lymphocytes, (C) neutrophils, (D) monocytes and (E) eosinophils (once accounted for capture date, year, body mass and sex effects). Dots represent the raw data with size proportional to the sample size. Dashed lines represent the best age model predictions with their standard error (dotted lines). The black and grey lines represent the between-individual and within-individual age effects with their associated standard errors (grey areas).

\section{Supporting Information}

Table S1: Pearson coefficients of correlation between the leukocyte concentration and the lymphocytes, neutrophils, monocytes and eosinophils counts. Values in brackets represent the $95 \%$ confidence intervals. 
Significant correlations are in bold.

Table S2: Model selection for age effects on leukocyte concentration, lymphocyte, neutrophil, monocyte and eosinophil counts. Body mass at capture, sex, capture date, year of capture and the interaction between capture date and year of capture were included as fixed effects. Because individuals were sampled several times over the years, we included the identity of the individuals as random intercepts. Models are ordered from the lowest (best model) to the highest Akaike Information Criterion (AIC). $k$ represents the number of parameters in the fitted model and $\triangle$ AIC the AIC difference between the model and the model with the lowest AIC.

Table S3: Model selection based on the Akaike Information Criterion (AIC) for the age models for leukocyte concentration (A), lymphocyte count (B), neutrophil count (C), monocyte count (D) and eosinophil count (E). Only the 10 most plausible models were presented and arranged from the best to the least plausible. $\triangle$ AIC represents the AIC difference between the model and the model with the lowest AIC. The best model and competitive models ( $\triangle$ AICc [?] 2) are presented in bold. The '+' indicates that the variable is included in the model.

Table S4: Model selection based on the Akaike Information Criterion (AIC) for the within- and betweenindividual age models for leukocyte concentration (A), lymphocyte count (B), neutrophil count (C), monocyte count (D) and eosinophil count (E). Only the 10 most plausible models were presented and arranged from the best to the least plausible. $\triangle$ AIC represents the AIC difference between the model and the model with the lowest AIC. The best model and competitive models ( $\triangle$ AICc [?] 2) are presented in bold. The '+' indicates that the variable is included in the model. 

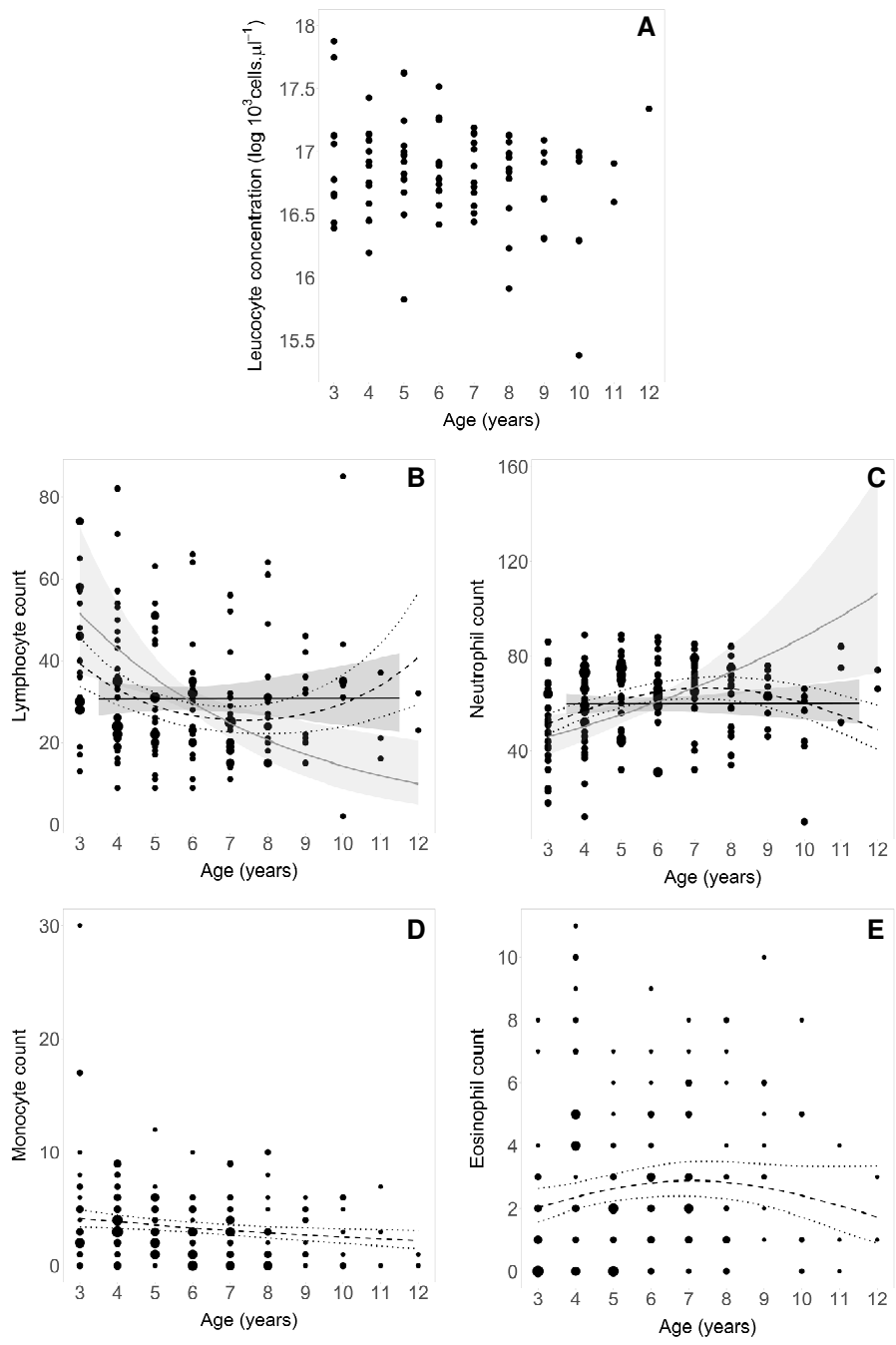